\title{
A DISSEMINAÇÃO DO MODO INDUSTRIAL: O EXEMPLO DE CAICÓ, NO RIO GRANDE DO NORTE ${ }^{1}$
}

\author{
Eliseu Savério SPOSITO
}

\begin{abstract}
Resumo: A industrialização brasileira é tema há muito tempo estudado em várias ciências sociais. Neste texto, fazendo uma abordagem geográfica, o tema é enfocado a partir de uma visão diferente: trata-se de demonstrar que, a partir da ideia de disseminação de modo industrial, o processo de industrialização não concerne a todos os territórios onde se localizam os estabelecimentos industriais mesmo que, de maneira geral, possam ser encontradas fábricas e empresas industriais em todos os estados brasileiros. Para defender essa tese, parti das primeiras manifestações da produção industrial (sem omitir o artesanato e a manufatura) para chegar ao exemplo das bonelarias em Caicó, Rio Grande do Norte.
\end{abstract}

Palavras-chave: industrialização, disseminação do modo industrial, Rio Grande do Norte.

Abstract: Brazilian industrialization has long been studied in various social sciences. In this text, from a geographical approach, the theme is focused on a different view: it's demonstrated that, from the dissemination of industrial mode, the process of industrialization does not concern all the territories where industrial establishments are located even if, in general, factories and industrial companies can be found in all Brazilian states. In order to defend this thesis, I started with the first manifestations of industrial production (without omitting crafts and manufacturing) in order to reach the example of the bonelarias in Caicó, Rio Grande do Norte.

Keywords: industrialisation, dissemination of industrial mode, Rio Grande do Norte.

\section{INTRODUÇÃO EXPLICATIVA}

Este texto foi organizado diferentemente da forma tácita como são organizados os textos em Geografia. Geralmente se começa pela revisão bibliográfica para, depois, se fazer a apresentação e análise de dados empíricos ou de argumentos de autores que dialogam com o tema estudado para, no final, surgirem as ideias conclusivas. Neste caso, vou começar por apresentar uma descrição de como a manufatura se transforma em indústria e, depois, um quadro com os pares dialéticos que estruturam a comparação, por meio de suas características, entre o que se tornou consuetudinário chamar de processo de industrialização e da proposta que tenho elaborado, nos últimos textos, de interpretar o território brasileiro por meio da

\footnotetext{
1 Agradeço à leitura feita por Francisco Fransualdo Azevedo, pesquisador da Universidade Federal do Rio Grande do Norte, que apontou as falhas iniciais do texto e contribuiu para que ele fosse melhorado.

${ }^{2}$ Professor Titular do Departamento de Geografia da Universidade Estadual Paulista Júlio de Mesquita Filho (UNESP/PP). Pesquisador 1B do CNPq. Email: essposito@gmail.com.
} 
disseminação do modo industrial. Depois, vou fazer uma interpretação, à luz das ideias expostas, do processo de disseminação do modo industrial no estado do Rio Grande do Norte, tomando como referência empírica a produção de bonés em Caicó, município que exemplifica a concentração industrial associada à especialização de alguns ramos. A insistência em um conceito que se forma justifica-se, portanto, pela exposição do exemplo de um ramo da pequena indústria no estado por meio da informação geográfica e das evidências empíricas decorrentes dos dados e da observação direta.

\section{ARTESANATO, MANUFATURA E INDÚSTRIA}

Entendo a industrialização como a forma como a sociedade se organiza para se apropriar da natureza para transformar os recursos em objetos (produtos) que serão consumidos em diferentes graus de intensidade (quantidade de produtos por pessoa; diferenciação social) e em diferentes lugares no mundo (porções da sociedade que se organizam de maneira desigual e combinada). Para que ocorresse a produção, as pessoas se organizaram historicamente. Partindo do momento em que se configura a manufatura na Europa, a necessidade da produção ocorre por causa de: 1) mudança na divisão social e territorial do trabalho; 2) utilização de ferramentas na potencialização da força e da qualificação humanas; 3) mudança no uso do tempo durante o dia, consolidando a diferença entre o campo e a cidade; 4) crescente urbanização e sistematização dos caminhos para deslocamento de pessoas e mercadorias ${ }^{3}$.

As mudanças no campo (transformação da terra em mercadoria; liberação da mão de obra dos camponeses que estavam atrelados, de maneira telúrica, às posses feudais; processo de migração do campo para a cidade) provocaram mudanças imediatas na cidade (processo de migração que aumenta a população urbana ao redor das muralhas das cidades; divisão do trabalho mais complexa; ampliação das atividades no dia por causa da iluminação artificial dos ambientes de trabalho; a remuneração do trabalho medida pelas horas e trabalho etc.).

Se tomamos como mero exemplo a produção de calçados, podemos imaginar como se conformava a divisão do trabalho. O camponês que se torna proprietário de sua força de trabalho e que tem alguma habilidade, passa a produzir calçados. Para isso, instala-se nas

\footnotetext{
${ }^{3}$ Não se trata, aqui, de esgotar os aspectos que marcam o início da manufatura na Europa. Quero, apenas, destacar alguns aspectos que considero fundamentais para demonstrar que a industrialização se origina por meio da complexificação da manufatura.
} 
proximidades das muralhas de uma cidade (ou produz, para o consumo daqueles mais próximos, em sua residência na área rural), aproveitando uma encruzilhada de estradas e, em um pequeno terreno, tem um pequeno rebando que lhe fornece leite, carne e couro (neste caso, para produzir calçados). Enquanto ele se ocupa da produção de calçados, sua família cuida do rebanho e da produção de alimentos. O trabalho é regido pelo tempo cósmico; ou seja, depende das estações do ano. O artesão se encarrega de sacrificar o animal, preparar e cortar o couro, costurar e vender. O calçado é feito segundo a medida daquele que vai comprar, o que limita a produção do artesão e faz com que seu trabalho dependa da demanda por calçados, em mercado que se forma, mas que não lhe dá garantia de fluxo regular da mercadoria que produz. Considerando que as pessoas são diferentes e, portanto, têm pés de tamanhos diferentes, a produção de calçados era feita, grosso modo, por "encomenda". A existência do produto dependia da existência do cliente que, por sua vez, não se apresentava em grande número porque as vilas não concentravam muitas pessoas. $\mathrm{O}$ artesão, que quer aumentar sua produção, depende de si e de sua família para fazer todos os procedimentos decorrentes do processo de produção.

Para Huberman, "a indústria se fazia em casa" porque, na passagem do feudalismo para o mercantilismo, "o propósito da produção era simplesmente o de satisfazer as necessidades domésticas" (1986, p. 53). Nos feudos, alguns trabalhavam no campo e outros, os servos domésticos, ocupavam-se apenas da produção artesanal.

O momento seguinte se define pela entrada de um intermediário que, por diversas razões (habilidade comercial, disponibilidade de tempo, domínio de algum conhecimento mercantil...) passa a ser o encarregado de tomar a produção de calçados e oferecê-la ao mercado. Aí temos uma mudança: se o artesão produzia o calçado e o vendia em sua residência, o intermediário pode vender os produtos longe de sua casa. Ele estabelece algum local ("ponto"), mais próximo dos clientes (uma esquina na área central da vila, uma loja fora das muralhas em alguma encruzilhada etc) ou de possíveis clientes que poderiam passar pela frente de seu negócio. A divisão do trabalho se modifica. Temos, agora, um produtor (o artesão) e um vendedor (o comerciante), além da divisão territorial do trabalho se tornar evidente, com as atividades ocorrendo em diferentes lugares.

A produção pode, também, aumentar. Para isso, o artesão precisa contar com mais pessoas que empreguem sua mão de obra na produção. Além de sua família, ele pode contratar alguém que se especialize em uma das atividades da produção de calçados. Essa 
pessoa pode se tornar hábil em cortar o couro, em cuidar dos animais que fornecem o couro ou pode dominar a costura do calçado em seu acabamento final. Para isso, ele gasta seu tempo vendendo sua força de trabalho em troca de dinheiro. O pagamento do salário é feito de acordo com seu tempo de dedicação ao trabalho (para isso, o papel do relógio foi fundamental). E a dedicação ao trabalho depende de sua capacidade física e intelectual de exercer a atividade. A capacidade física vai mostrar quanto tempo ele pode se dedicar à produção e capacidade intelectual será fundamental para que ele domine os processos de produção sob seu encargo. Além da família do artesão, que ajudava na produção sem receber remuneração, agora temos alguém mais que se agrega ao processo produtivo recebendo, pela venda de sua força de trabalho, uma quantia de dinheiro proporcional ao tempo dedicado. A divisão do trabalho se torna mais complexa e entra, no cenário, o assalariamento. A relação também se modifica. De membros de uma mesma família, o outro elemento presente, fora dela, que recebe salário, se consubstancia pela relação entre pagador e recebedor. O pagador assume a posição de quem tem dinheiro para adiantar o pagamento do assalariado antes da venda de sua produção, e o assalariado vai depender, para sua sobrevivência e reprodução social, do pagamento pelas horas de trabalho que dedica à produção de calçados.

Huberman afirma que "o progresso das cidades e o uso do dinheiro deram aos artesãos uma oportunidade de abandonar a agricultura e viver de seu ofício" (1986, p. 53). Era o domínio do conhecimento tácito propiciando o surgimento da profissão que iria dar identidade à produção industrial. A unidade típica era uma "pequena oficina, tendo um mestre como empregador em pequena escala, trabalhando lado a lado com seus ajudantes" (idem, p. 54).

Para Pirenne (1955), “cada vila, grande ou pequena, possui um número e uma diversidade, proporcionais a sua importância", tanto de "artesãos de primeira categoria, pois nenhuma burguesia pode prescindir dos objetos fabricados que exige a satisfação de suas necessidades" (p. 130). Enfim, a "clientela das pequenas oficinas urbanas está, pois, formada ao mesmo tempo pela burguesia local e pela população rural circunvizinha” (p. 131).

O que temos é a clara divisão do trabalho, em termos de função (atividade concernente ao processo de produção) e de espaço (atividades em diferentes partes do território, mesmo que ainda em distâncias pequenas); além disso, há o pagamento pela venda da força de trabalho estabelecida pela relação entre assalariado (trabalho) e pagador (capital). O pagador, detentor do capital, é o protótipo do capitalista. Para completar esse quadro, surgem as corporações de ofício que empregam pessoas do mesmo ramo de trabalho, sendo todos (os mestres artesão, os jornaleiros, os aprendizes) pertencentes ao mesmo grupo, que se 
preocupava com os seus membros. A tendência à monopolização se torna evidente e as corporações eram intolerantes com qualquer interferência externa.

Continuamos lendo o tempo. A produção do artesão cresce mais porque, com a migração dos camponeses para as vilas e as cidades, elas crescem e as pessoas precisam de calçados. Ele precisa produzir cada vez mais. Para isso, precisa de mais ferramentas e mais pessoas. O espaço de sua residência é pequeno para a demanda que se torna maior (e, por que não?) necessária. Ele consegue uma edificação, distante de sua casa, mais próximo dos potenciais empregados e dos clientes. Ele tem, a partir daí, um distanciamento entre o local da produção e o seu local de moradia. A divisão territorial do trabalho faz com que sua produção se distancie do local de reprodução de sua força de trabalho inicial (a família) e de sua posição como capitalista. Ele precisa que alguém seja especialista nas ferramentas (facas, agulhas...), de alguém que saiba cuidar dos animais e curtir o couro, de alguém que venda sua produção e, até mesmo, alguém que tenha noção de como cuidar das finanças da empresa porque ele não tem tempo para isso. A divisão do trabalho se torna mais complexa. Como sua produção aumenta por causa do aumento da procura (aqui chamo de mercado), ele pode, por causa da divisão do trabalho e, portanto, da especialização das atividades de seus empregados, fazer com que todos tenham apenas uma função na produção do calçado. Um se encarrega do tratamento do couro, outro do corte do couro de acordo com os tamanhos possíveis de calçados, outro se encarrega da costura e outro do acabamento, polindo e engraxando o calçado para que sua aparência agrade ao futuro comprador. A especialização faz com que, com o domínio de apenas uma atividade na produção de calçado, o assalariado aumente o ritmo de sua produção e, consequentemente, aumente o número de produtos e tenha a possibilidade de ganhar mais.

No entanto, com o aumento da população urbana, o aumento da oferta de vendedores da força de trabalho faz com que a concorrência pelos empregos também aumente. A existência de uma reserva de mão de obra serve como termômetro para que o capitalista não aumente, como merece o trabalhador, seu salário. Ele pode reivindicar, mas se não quiser mais o emprego, outros estão prontos a aprender como fazer calçados e a vender sua força de trabalho.

Huberman lembra que "a noção do que constituía o justo preço das mercadorias era natural, antes que o comércio se ampliasse ou as cidades crescessem”. No entanto, o “desenvolvimento do mercado (...) e a produção em grande escala (...) provocaram uma 
modificação das ideias econômicas, e o justo preço acabou sendo substituído pelo preço de mercado" (1986, p. 61). A existência da produção industrial, dos jornaleiros, dos patrões, da formação do mercado consumidor leva à necessidade de se vender os produtos em troca de dinheiro. Aí é necessário formar o preço. E ele se molda mais às condições do mercado que como resultado do trabalho incorporado ao produto.

O tempo cósmico, que regulava a produção do artesão, torna-se secundário. Com a aglomeração de vários trabalhadores em um mesmo lugar, mais amplo, com luz artificial (propiciada pelos archotes, depois, bem mais tarde, por uma grande invenção humana, a lâmpada incandescente), amplia o tempo dentro da fábrica. Aumenta o número de horas que o trabalhador pode ficar exercendo sua profissão em troca da venda do seu trabalho. Como a concorrência da mão de obra represa suas reivindicações, ele trabalha mais e ganha menos para não perder o emprego. Como o tempo regula seu salário, sua produção, que é contada em horas, pode se estender por mais tempo do que a luz do sol permite. Amplia-se, assim, o tempo de produção e, consequentemente, a quantidade produzida. $\mathrm{O}$ mercado se amplia, a demanda é atendida, a população urbana aumenta, o tamanho da cidade aumenta e as pessoas precisam se deslocar, em distâncias maiores, para produzir (em troca de salário) e consumir (tanto precisam se alimentar, levando seus alimentos da residência, como utilizar os produtos necessários para suas atividades, como facas, agulhas e graxas). A cidade se expande porque, de forma geral, criam-se estruturas de encanamento e esgotos, por exemplo, que vão propiciar o saneamento necessário para que a saúde pública garanta a longevidade das populações.

divisão do trabalho se torna mais complexa, a distância entre o capitalista e o assalariado aumenta e a pressão dos que querem emprego aumenta a instabilidade de quem está empregado. Mas o domínio de certas habilidades faz com que alguns trabalhadores sejam essenciais no processo produtivo. Eles dominam, melhor que outros, certos procedimentos e querem, para ganhar mais ou garantir seus empregos, lembrar aos patrões a sua importância. Se deixarem de trabalhar, não haverá produção e não haverá venda de produtos. Os patrões vão precisar deles senão não terão seus ganhos garantidos. Será interrompido o processo produtivo. O trunfo dos trabalhadores, historicamente, passou a se chamar greve. As paradas não agradavam aos patrões pois, para sua ideologia burguesa, não ganhar significava não garantir sua acumulação capitalista e, portanto, não garantia sua riqueza. Sua riqueza era importante para ele ter um distanciamento cada vez maior de seus empregados e para sua ascensão social, inserindo-se em grupos aristocráticos ou garantindo casamentos de seus filhos com pessoas de origem aristocrática. 
O trabalhador, no entanto, não contava com a repressão policial. Em nome da lei, como o Estado é um pacto social, os burgueses têm o respaldo do Estado para garantir a “ordem" porque a produção garante, também, o pagamento de impostos aos governos que precisam deles para manter seus gastos... e manter a polícia. O círculo que se forma, entre o pagamento dos impostos, a manutenção da polícia, a força política da burguesia, sua aspiração a fazer parte de uma aristocracia decadente e a necessidade de suprir o mercado (a produção de calçados precisa atender, também, os outros burgueses e a aristocracia) conforma as diferentes determinações que se resumem no ciclo produtivo: produção, circulação, troca e consumo. As mortes de trabalhadores provocadas pela repressão policial, o desmantelamento das formas de organização dos trabalhadores (pela lei ou pela força), fazem com que a reserva de mão de obra e o papel do Estado garantam os salários no patamar que interessa aos patrões. As corporações foram se distanciando, dividindo-se em dois grupos: dos mestres, de um lado, e dos jornaleiros - assalariados - de outro. O aumento da distância entre eles levou à formação de corporações próprias. Os jornaleiros reivindicavam seus salários, enfrentando a resistência dos patrões. Os assalariados, em grande número nas cidades, "viviam em buracos miseráveis e doentios, não tinham nem a matéria prima nem as ferramentas com que trabalhavam" (Huberman, 1986, p. 67). Eles formariam o que seria, posteriormente, o proletário moderno que tem, por seu lado, "apenas seu trabalho" para vender, "dependendo do empregador e de condições favoráveis de mercado pra sua sobrevivência" (Huberman, 1986, p. 67).

Garantidas as possibilidades de produção, os patrões aspiram, amparados pela ideologia capitalista, por meio da acumulação constante e crescente, novas possibilidades para aumentar a produção. Novas ferramentas e novas formas de distribuição dos trabalhadores no chão da fábrica fazem com que a manufatura se transforme em indústria. Como forma das pessoas se organizarem para, amparadas pela potencialização de suas forças dominarem as forças da natureza, o domínio desta se torna mais evidente. As ferramentas se aprimoram. Os conhecimentos são fundamentais: a força do vento, das águas, a articulação das rodas em engrenagens etc, fazem com que a força humana se torne cada vez menor perante o conhecimento humano. É a ciência oferecendo possibilidades para se dominar e transformar a natureza, potencializando a força e o conhecimento humano.

A roda possibilita a instalação das linhas de produção. O conhecimento da força da água e dos metais permite o domínio da força potencial que faz mover as máquinas (desde os 
teares hidráulicos até as locomotivas movidas a vapor) e, mais tarde, a obtenção da eletricidade. Esta, por sua vez, serve de fonte de energia para as máquinas e para iluminar os ambientes de trabalho. São necessárias, para isso, inúmeras pessoas com suas diferentes especialidades para fazer com que tudo, desde a produção de calçados até à manutenção das máquinas, a condução das locomotivas, dos navios e das carruagens, para que os sistemas funcionem e a produção e o consumo ocorram, mediados pela distribuição dos produtos. A moeda é fundamental para o pagamento dos salários e das mercadorias. O capital se amplia porque a acumulação é estimulada pelo aumento do dinheiro nas mãos dos capitalistas. Os bancos são parte desse círculo porque podem vender o dinheiro e receber por essa venda, multiplicando-o sem que ele entre no processo produtivo, ou seja, sem que ele seja a soma de inúmeras quantias de mais valia não pagas aos assalariados. Mesmo assim, os bancos são importantes para financiar novos negócios industriais, adiantando o capital necessário para a construção das edificações, para a compra das máquinas e do primeiro estoque de matérias primas.

A convivência entre a burguesia enriquecida pelas mudanças na ideologia do trato com o dinheiro e os miseráveis, era visível na paisagem urbana. Os motivos podiam ser as guerras mas, também, o excedente de mão de obra que se alojava nas cidades com as mudanças estruturais que ocorreram nos campos. A ampliação dos horizontes para a América provoca o fluxo de ouro e prata para a Europa que leva ao enriquecimento de uma minoria e teve, como consequência, o aumento dos preços; e, aí, inclui-se a produção industrial.

Huberman (1986) afirma que a organização industrial pode ser classificada em quatro grupos: 1) sistema familiar (produção dos membros de uma família para consumo direto, sem necessidade de buscar o mercado); 2) sistema de corporações, quando "a produção era realizada por mestres artesãos independentes" visando "o mercado, com produção pequena"; 3) sistema doméstico, pois a produção, "realizada em casa", visava um "mercado em crescimento" e balizado pelo fato de que os artesãos "dependiam, para a matéria prima, de um empreendedor que se interpusera entre eles e o consumidor"; e 4) sistema fabril, que predomina na atualidade, cuja produção visava "um mercado cada vez maior e oscilante, realizada fora de casa, nos edifícios do empregador e sob rigorosa supervisão" (p. 115), quando o capital se torna necessário e imprescindível. Estava claro o novo modo de produção, diferente do anterior, "baseado na livre troca de mercadorias com o objetivo primordial de obter lucro" que "foi introduzido pela burguesia" (p. 153). 
Huberman (1986) afirma que "a expansão do mercado (...) é uma chave importante para a compreensão das forças que produziram a indústria capitalista tal como a conhecemos" (p. 109). Aqui se consolida a figura do intermediário, já citado anteriormente, cuja atividade era "fazer com que as mercadorias produzidas pelos trabalhadores chegassem ao consumidor, que podia estar a milhares de quilômetros de distância” (p. 109).

O aumento do mercado consumidor deve ser balizado, também, pela incorporação tecnológica nos transportes e nas comunicações. Da máquina a vapor, passando pelo motor a explosão ao avião a jato, a distribuição das mercadorias é feita por diferentes modais terrestres, aéreos e aquáticos. As distâncias são vencidas em menor fração de tempo. $\mathrm{O}$ espaço é modificado pelo tempo em termos de deslocamento. As comunicações, com a invenção do telégrafo, depois do telefone e recentemente da internet, aceleram-se e a transmissão das informações alcança velocidade inestimável. A comunicação vai do uso dos fios telegráficos, passa pelo telefone e, atualmente, prescinde das conexões físicas porque há a comunicação sem fio.

A matéria prima para a produção continua importante, mas o conhecimento e o domínio de técnicas, novos materiais e a reorganização do trabalho nas fábricas, favorecem o aumento da produção. No sistema em série, típica do fordismo, a produção, por sua intensidade e padronização, define o tipo e as formas de consumo. Sua superação possibilita novas combinações e a demanda passa a ser mais importante porque incorpora características culturais em diferentes mercados como resultado das novas ideias e tecnologias, levando à produção de objetos em maior número que o de habitantes no planeta e, mais ainda, sem que isso seja necessário para as pessoas. $\mathrm{O}$ consumo passa a ser a causa da produção e não o resultado das necessidades das pessoas.

Essa introdução teve, como objetivo principal, situar o leitor na proposta do texto: mostrar como, historicamente, a consolidação do modo industrial se dissemina por meio da divisão territorial do trabalho e vai tomando conta não só do ramo da produção de calçados, mas de todos os produtos necessários (e supérfluos) consumidos pelas pessoas em diferentes intensidades, lugares e tempos. 


\section{AS CARACTERÍSTICAS DA DISSEMINAÇÃO DO MODO INDUSTRIAL. A TEORIA SE SUSTENTA NO EMPÍRICO: O CASO DE CAICÓ}

O quadro I contém pares dialéticos que se referem, de acordo com alguns princípios e recortes, a uma tentativa de comparação entre os processos de industrialização (lato sensu) e de disseminação do modo industrial. O entendimento desses pares foi feito levando-se em consideração, também, as características do modo capitalista de produção. É por aqui que começo minha argumentação para, depois, mirar com mais aprofundamento o quadro.

O quadro I foi organizado para mostrar a articulação de pares dialéticos que estruturam a industrialização em seu sentido lato. Não há hierarquia entre os pares destacados no quadro, mas há uma intencionalidade de articulação entre eles, no tempo e no espaço. O quadro serve, também, para confrontar aquilo que se chama de processo de industrialização com o que chamamos de disseminação do modo industrial.

Mais do que descrever cada um dos pares, sugiro ao leitor a observação do quadro e confrontá-lo com o que trabalharei a seguir por meio do exemplo de Caicó, no Rio Grande do Norte.

Vou iniciar a análise empírica de Caicó baseando-me em autores que estudaram a industrialização no Estado do Rio Grande do Norte. Silva (2011), por exemplo, analisou os índices de concentração industrial no Rio Grande do Norte. Para a autora, há evidências de aglomerações industriais pois, baseando-se em Silveira Neto (2005), afirma que se "entre os anos de 1950-1970, houve uma elevação da concentração industrial na Região Sudeste, explicada em larga medida pelo processo de substituição de importações”, no período seguinte (1970-1985) "ocorre uma significativa desconcentração industrial no Brasil, (...) devido às políticas de incentivo fiscal", o que leva a Região Nordeste a "apresentar sinais positivos de mudanças", pois ela "volta a ganhar peso no cenário nacional”. Essa tendência, segundo Silveira Neto (2005), ou seja, entre 1985 e 2000, “começa a perder suas forças, exigindo muito mais qualificação para que a mesma se dê numa maior intensidade." Nesse período "a região nordeste volta a perder espaço no cenário industrial da economia brasileira". (SILVA, 2011, p. 5).

Quadro I: Características do processo de industrialização e do 
processo de disseminação do modo ${ }^{4}$ industrial.

\begin{tabular}{|l|l|l|}
\hline $\begin{array}{l}\text { Princípios / } \\
\text { recortes }\end{array}$ & Processo de industrialização & Disseminação industrial \\
\hline Rede urbana & $\begin{array}{l}\text { Predominância das áreas } \\
\text { metropolitanas e aglomerações } \\
\text { urbanas }\end{array}$ & $\begin{array}{l}\text { Importância das cidades médias e } \\
\text { pequenas }\end{array}$ \\
\hline Interação espacial & Decisões das grandes empresas & $\begin{array}{l}\text { Estratégias para criar modos de } \\
\text { consumo }\end{array}$ \\
\hline Localização & $\begin{array}{l}\text { Concentrada; cidades; áreas de } \\
\text { produção de matérias primas }\end{array}$ & Difusa; disseminada pela rede urbana \\
\hline Aglomeração & Necessária & Contingente \\
\hline Hierarquia & Estrutural; vertical; forte & Heterarquia; múltipla \\
\hline Competitividade & $\begin{array}{l}\text { Produção padroniza o consumo, } \\
\text { padrão do produto; decrescente }\end{array}$ & $\begin{array}{l}\text { Consumo dirige a produção; } \\
\text { necessária; modelo Terceira Itália }\end{array}$ \\
\hline Cooperação & Linha de montagem & Segmentação das fases de produção \\
\hline Competição & $\begin{array}{l}\text { Tendência à monopolização; } \\
\text { crescente }\end{array}$ & $\begin{array}{l}\text { Concorrência pela terciarização e } \\
\text { terceirização; cooperação }\end{array}$ \\
\hline Flexibilidade & Não necessária & Necessária \\
\hline Temporalidade & Longo prazo & Instabilidade; prazos variados \\
\hline Tecnologia & Proporcional ao ramo & Conhecimento tácito x tecnológico \\
\hline $\begin{array}{l}\text { Transformações e } \\
\text { permanências }\end{array}$ & Tempo lento & $\begin{array}{l}\text { Frequentes e no curto prazo; tempo } \\
\text { rápido }\end{array}$ \\
\hline Consumo & Padronizado & “Customizado" \\
\hline DTT & $\begin{array}{l}\text { Densa, compacta; verticalizada; } \\
\text { intersetorial }\end{array}$ & $\begin{array}{l}\text { Difusa, ampliada; horizontalizada; } \\
\text { complementar }\end{array}$ \\
\hline Estado & Produtor, regulador & $\begin{array}{l}\text { Produção por grupos de produtos; } \\
\text { não estoque }\end{array}$ \\
\hline Chão da fábrica & $\begin{array}{l}\text { Produção em série; linha de } \\
\text { montagem; estoque }\end{array}$ & \\
\hline
\end{tabular}

Organização: Eliseu S. Sposito

Silva (2011) afirma que Domingues (2005) “concluiu que, no Brasil, 26\% das firmas são inovadoras, diferenciam produtos e formam preços"; por outro lado, "66\% são firmas especializadas em produtos padronizados e tomadoras de preços”, o que leva à conclusão de que há tendência, no país, ao domínio do conhecimento tácito e pouca importância à inovação. Além disso, "8\% são firmas que não diferenciam produto, não exportam e têm produtividade menor" (SILVA, 2011, p. 5). A economia na "região nordeste, em particular, é bastante desigual", considerando que "no cenário nacional existem regiões que apresentam fortes ligações industriais, que resultam em elevados aspectos de desenvolvimento, mas ocorrem também regiões isoladas com pontos industriais sem conexões e limitados efeitos de

\footnotetext{
${ }^{4}$ Modo, aqui, tenho usado em seu sentido etimilógico original: substantivo que significa "maneira de ser ou de expressão, procedimento". Por isso, posso definir o modo de produção industrial como a maneira como as pessoas, considerando a divisão do trabalho em ambiente capitalista, se organizam para trnasformar elementos da natureza em objetos que serão consumidos pela sociedade em diferentes momentos e intensidade.
} 
transbordamentos" (SILVA, 2011, p. 5). É possível afirmar, com certeza, que esta característica é mais uma evidência da disseminação do modo industrial no Rio Grande do Norte, associada a outra evidência que é a instabilidade na produção ao longo do tempo porque as externalidades (oscilações na economia do país, diminuição dos fluxos de exportação) incidem diretamente no comportamento das economias locais, principalmente no setor industrial de bens não duráveis. Em 1994, por exemplo, Caicó comparecia com 0,90\% do total de empregos industriais no RN. Esse número aumenta para 2,82\% em 2000 e decresce, em 2009, a 2,24\% ${ }^{5}$. Esses dados mostram um crescimento em seis anos e um decréscimo nos nove anos seguintes, conformados pela tendência geral da economia brasileira.

Caicó tem característica produtiva parecida com os municípios de Natal e Mossoró, pois tem coeficientes de especialização ${ }^{6}$ abaixo de 0,4 no período de 1994 a 2009. No entanto, entre 1999 e 2001, teve índice de 0.2. Silva (2001) conclui que "foi possível observar como evoluiu a concentração industrial e a especialização regional nos municípios do Estado do Rio Grande do Norte". A autora verificou, "o nível de sua evolução com análises da concentração industrial e especialização regional voltada, especificamente para distribuição espacial" (SILVA, 2001, p. 15). Para essa autora, o resultado do coeficiente de especialização pode variar de 0 a 1 , em que quanto mais próximo de 0 , mais diversificada é a atividade industrial no município, o que reflete uma composição setorial idêntica à do Estado, e quanto mais próximo de 1, mais elevado é o grau de especialização do município" (SILVA, 2001, p. 11). Esse índice, na escala indicada ( 0 a 1 ) é resultado de cálculos do índice de Gini a partir de dados da RAIS (Relação Anual de Informação Social), banco de dados disponível no Ministério do Trabalho no Brasil.

Portanto, conforme analisado, é possível concluir que o estado do Rio Grande do Norte tem uma estrutura produtiva pouco desenvolvida, com predominância de acentuadas taxas de concentração industrial e, ao mesmo tempo, uma forte presença de municípios especializados que proporcionam ao estado a ausência de uma estrutura produtiva diversificada (SILVA, 2001, p. 16)

\footnotetext{
${ }^{5}$ Dados elaborados por Joelma B. da Silva a partir da RAIS (1994-2009).

${ }^{6}$ Para melhor visualização dos coeficientes de especialização no Rio Grande do Norte, indico a leitura do texto citado: SILVA, Joelma A. B. da. Dinâmica do emprego industrial nos municípios do Estado do Rio Grande do Norte, no período de 1994-2009. Brasília: IPEA, Code 2011, Anais do I Circuito de Debates Acadêmicos, 2011.
} 
Para demonstrar como se dissemina o modo industrial, tomo como exemplo a produção de bonés em Caicó como atividade importante no Seridó, região do Rio Grande do Norte. A produção de bonés em Caicó comporta várias determinações mostradas na introdução e no quadro I. A produção de bonés é o resultado mais claro da disseminação do conhecimento tácito do que da criação de novas tecnologias de produção ou novos materiais. A matéria prima é o tecido, comprado no centro-sul do país. A divisão do trabalho concretizase, portanto, na produção do tecido que se desloca no território brasileiro, por caminhão principalmente, do centro-sul para o nordeste. O corte dos tecidos para a montagem posterior dos bonés é feito, nas várias fábricas, incorporando diferentes tempos tecnológicos: desde a tesoura até o raio laser. As formas de corte auxiliam na velocidade e na quantidade da produção. O domínio da tecnologia exige, também, capacidade técnica dos trabalhadores e conhecimento, por parte do empresário, de onde adquirir a tecnologia e como engajar os trabalhadores.

A tinta para colorir os tecidos, estampar os desenhos e as marcas nos produtos não é fabricada no nordeste brasileiro. As máquinas de costura são provenientes do centro-sul do país ou do exterior. Para operar as máquinas, o aprendizado por parte dos trabalhadores é definido pelo tempo e por sua capacidade de dominar o conhecimento incorporado nelas. A habilidade conta, aí, para diferenciar as diferentes pessoas que vendem sua força de trabalho. O conhecimento tácito se dissemina quando um trabalhador deixa uma empresa e passa a, ele mesmo, a produzir bonés e reproduzir os mecanismos de compra de matérias primas, produção e venda de bonés em sua própria residência.

Os ambientes de produção, conhecidos como facções, são pequenos. Podem ou não ser ambientes domésticos (como no início das manufaturas). São prédios próprios mas há muitos alugados que geram renda fundiária a seus proprietários, que entram na divisão do trabalho como capitalistas que não se encarregam de pagar salários, mas acumulam parte da mais valia não paga em forma de renda. Tanto o patrão como os empregados não residem no prédio da fábrica e, por isso, precisam se deslocar na cidade entre a residência e o local de trabalho ou, como podem residir na zona rural, precisam vencer distâncias maiores ou, mais ainda, quando se deslocam entre diferentes municípios, como entre Cruzeta e São José do Seridó, sendo que em Cruzeta há seis facções e em São José do Seridó mais de dez.

A cidade de Caicó concentra 67.259 habitantes (estimativa do IBGE para 2015), tem PIB municipal equivalente a $\mathrm{R} \$ 786.585$ mil e PIB per capita de $\mathrm{R} \$ 11.041,64$ (estimativas do 
IBGE para 2012). O município tem a superfície de $1.228,574 \mathrm{~km}^{2}$. Em 2009, a cidade contava com 381 estabelecimentos industriais (bonés, sorvetes, café etc, que equivalia a 9,7\% entre todas as empresas atuantes no município, que eram 1.457 unidades atuantes), com crescimento significativo em relação a 1991, quando contava com 141 unidades industriais. O total de assalariados era, em 2013 (dados do IBGE), 9.795 pessoas que recebiam, em média, 1,6 salários mínimos.

Por suas dimensões (populacional, econômica) ela tem sua posição específica na rede urbana e contém seu papel na divisão territorial do trabalho ao conter as fábricas de bonés. Outro aspecto a lembrar é fundamental: mesmo que haja fábricas distribuídas pela cidade, o evento da produção domiciliar, em algum ambiente da residência de uma pessoa que terceiriza parte da produção faz com que uma das evidências do início da produção industrial se manifeste em Caicó: é a produção na residência de alguém que domina o conhecimento tácito da produção de boné e se encarrega de produzir parte da produção de uma empresa maior. A convivência entre o ambiente fabril, baseado na maquinofatura, e o ambiente doméstico é uma das características da disseminação do modo industrial no início do século XXI. No entanto, em 2015, 563 pessoas com 10 anos ou mais de idade, segundo o IBGE, exerciam o trabalho principal em mais de um município, o que permite deduzir que o deslocamento das pessoas é uma decorrência da divisão territorial do trabalho e, por conseguinte, que é preciso trabalhar em outro sítio que não o local de moradia.

A cidade de Caicó estende-se, de norte a sul, por $5,5 \mathrm{~km}$ e, de leste a oeste, por $6 \mathrm{~km}$. Quem mora distante do seu local de trabalho, precisa se deslocar a pé, de ônibus ou em veículo próprio, que pode ser automóvel, motocicleta ou bicicleta. Os veículos utilizados contêm as diferentes tecnologias que propiciam a convivência de formas e tempos diferentes na cidade e, portanto, na mobilidade das pessoas, o que dá a elas diferentes tempos, conforto e custos de deslocamento. Embora no contexto atual o deslocamento de mão de obra vinculada ao circuito de produção têxtil (produção de bonés), o transporte por meio de motocicleta é importante o que acarreta efeitos sobre o comércio de motocicletas e peças para esse tipo de veículo, e sobre os serviços para sua de assistência técnica e manutenção.

Essa característica do modo industrial na cidade torna-se mais penoso para os deslocamentos porque as facções podem se localizar, também, nas áreas rurais do município. Assim, pode se afirmar que a divisão do trabalho dentro da unidade industrial se replica na divisão territorial do trabalho e vice-versa. 
A produção dos bonés não visa o mercado local, embora eles também possam ser comercializados e consumidos na cidade. Eles são exportados para o centro-sul do Brasil, litoral nordestino (inclusive, espaços turistificados) ou para o exterior. São mercados distantes, alcançados pelo transporte rodoviário que leva grandes quantidades de bonés para o consumo indiscriminado nas cidades das regiões do centro-sul. A venda dos bonés resulta no pagamento dos salários dos trabalhadores, descontada a mais valia não paga que se metamorfoseia em lucro para o capitalista.

A produção de bonés em Caicó pode ser classificada como produção industrial. No entanto, ela não é exclusiva porque não torna o município a única área de produção (ela ocorre, também, em São José do Seridó e Jardim das Piranhas, por exemplo). Não houve, tampouco, um processo de industrialização em Caicó e nos municípios próximos, embora a produção industrial ocorra. A formação de um possível arranjo produtivo local não pereniza a produção industrial na área. Mas não podemos negar que a produção é industrial. Assim, qual é a contradição que emerge? Fica clara a disseminação do modo industrial, mas não a efetivação de um processo de industrialização. As fábricas (e a produção em ambiente doméstico) abrigam a divisão social do trabalho, propiciam a realização da mais valia, levam à produção de produtos com diferentes níveis tecnológicos, são organizadas em formas mais próximas às manufaturas ou à produção mediada pela máquina. Mas se atêm aos próprios limites de seu alcance: entre a manufatura e a fábrica, ficam entre as duas. Incorporam conhecimentos tácitos, expõem a divisão territorial e social do trabalho, sustentam a acumulação capitalista e mantêm mercados distantes que precisam de bonés para consumir. Mas não estão, como resultado que são da disseminação industrial, na base das transformações típicas da industrialização: não se produzem máquinas ali para a produção de bonés nem se consome a maior parte da produção.

As bonelarias têm sua produção em série e uma forma de linha de montagem precária. Desde a compra do tecido, o corte (em muitos casos por raio laser, o que indica incorporação tecnológica avançada), a estampa (com tintas provenientes de outras áreas, principalmente do exterior) e a costura dos bonés realizada com o domínio tácito da técnica intermediada por máquinas de costura (também provenientes do centro-sul do Brasil ou do exterior), a produção ocorre em bancadas fixas e as pessoas se movimentam de acordo com a etapa da produção. 
Esse ramo industrial ocorre, em várias partes da cidade, no interior de estabelecimentos industriais vinculados a pequenas e micro empresas: segundo a FIERN (Federação das Indústrias do Rio Grande do Norte), dos 37 estabelecimentos que fabricam bonés, dois têm 50 funcionários, 25 têm entre 10 a 49 empregados, e 10 estabelecimentos têm até 9 funcionários. As dimensões dos estabelecimentos mostram que, como as empresas podem ser classificadas como micro ou pequenas, a presença da mão de obra familiar e pouco especializada pode ser uma constante em grande parte delas. No entanto, repetindo o que já foi afirmado, o conhecimento tácito se dissemina como saber-fazer que nos produtos se incorpora.

Tabela 1 - CAICÓ /RN - Estabelecimentos industriais e empregos formais - 2014

\begin{tabular}{c|c|c}
\hline Setor de atividade & Estabelecimentos & Empregos formais \\
\hline Indústria extrativa & 3 & 24 \\
\hline $\begin{array}{c}\text { Indústria de } \\
\text { transformação }\end{array}$ & 201 & 2.200 \\
\hline Fabricação de bonés & $37(18,4 \%)$ & $579(26,3 \%)$ \\
\hline Construção civil & 28 & 288 \\
\hline Total & 32 & 2.512 \\
\hline
\end{tabular}

Fonte: Cadastro Industrial FIERN, 2014.

O Estado comparece, intermediado pelo município, como incentivador da instalação de estabelecimentos industriais por meio da concessão de lotes em áreas específicas para as atividades de transformação. A divisão do trabalho mostra-se horizontalizada e complementar a outras atividades porque, neste caso, o operário pode residir, inclusive, em áreas rurais e ser proprietário de terra. A flexibilidade torna-se elemento importante e necessário na divisão do trabalho porque o domínio de vários momentos da produção é importante para o trabalhador. A competição se mostra pela concorrência por meio da terciarização, possibilitando a prática da cooperação (no sentido marxiano do termo) formada pela aglomeração de estabelecimentos industriais na área urbana. Ela é dada, também, pela segmentação das fases de produção, lembrando as mudanças na complexidade da divisão do trabalho, como já vimos anteriormente.

O consumo dos bonés obedece a regras tanto do sistema fordista quanto da produção flexível: são padronizados, dependendo dos lotes encomendados e são "customizados" porque se direciona a produção para um tipo específico de consumidor (jovem, de empresa, pessoa esportista etc). O consumo torna-se necessário porque os produtos conformam o mercado que, por sua vez, "dirige" a produção. 
A localização das indústrias é disseminada por toda a cidade, embora haja áreas específicas para a concentração da atividade industrial. Desde os estabelecimentos fixados em prédios próprios, com identidade visual aparente, até aqueles localizados nos fundos das casas de pessoas que terceirizam a produção das fábricas maiores, quando isso for necessário.

As transformações, quando se trata do espaço urbano, são frequentes e nos curto e médio prazos; o tempo rápido é a medida do trabalho no chão da fábrica e nas relações de trabalho, diferentemente das transformações fordistas, que eram marcadas pelo tempo lento e pelas permanências na paisagem dadas pelos edifícios onde se instalavam as indústrias.

No que concerne ao domínio tecnológico, as diferenças são evidentes: podemos afirmar que há uma relação dialética entre o conhecimento tácito e o domínio da tecnologia (raio laser, computador, máquinas automáticas), numa tensão de permanência e superação de técnicas mais próximas da manufatura que do tempo industrial. O domínio tecnológico dá, em termos de tempo de realização da produção, em prazos variados e certa instabilidade medida pelos mercados e não pela capacidade produtiva dos estabelecimentos. A circulação das mercadorias que, na fase fordista, ocorre em grandes quantidades, atualmente ocorre por demanda, com grande rapidez e fluidez territorial.

Quando olhamos para a rede urbana, a disseminação do modo industrial comporta-se diferentemente na atual fase em relação ao fordismo. Se, neste modo, a hierarquia urbana é estrutural, vertical e forte, no caso da produção flexível podemos falar em heterarquia urbana (Catelan, 2013) de conformação múltipla e não vertical. Se, no fordismo, a predominância era das áreas metropolitanas e das aglomerações urbanas como locais de maior densidade e força da industrialização, a importância das cidades médias e pequenas se fortalece como territórios da disseminação do modo industrial. Outro aspecto importante é a interação espacial que pode ser exemplificada pelas estratégias das empresas para criar potencialidades de consumo. Para isso, a aglomeração urbana é contingente e não necessária.

Os princípios e recortes explicados acima não podem ser encarados de maneira absoluta, mas como elementos que estruturam e se reestruturam, que se relativizam, que se negam e confirmam na divisão territorial do trabalho sem, necessariamente, um se tornar mais importante que o outro em termos absolutos, mas relativizados de acordo com o tempo da produção e da existência do estabelecimento industrial e de acordo com a localização e a capacidade de gerar emprego e colocar, para o consumo, uma produção com magnitude correspondente à capacidade que a empresa tem de participar do mercado. 
Além da comparação entre as características do fordismo e da produção flexível, precisamos lembrar o início deste texto, quando foram descritas as mudanças na divisão do trabalho e o que ocorreu nas cidades. Caicó tem produção industrial que demonstra a convivência de diferentes tempos nos processos produtivos, desde pequenas produções que lembram as manufaturas dos séculos XIX e XX a estabelecimentos industriais que se beneficiam de tecnologias avançadas. A divisão do trabalho se modifica tanto dentro da fábrica (entre as atividades exercidas pelos trabalhadores) quanto no distanciamento entre a produção e o consumo dado pela possibilidade de realização do consumo em mercado distante da cidade. A localização industrial, desde sua dispersão pela cidade quanto a concentração em “distritos industriais", apresenta caráter heterogêneo neste aspecto, levando ao deslocamento da força de trabalho e o açodamento do uso dos meios de transporte, sejam eles coletivo ou individual.

A cidade comporta estabelecimentos industriais. Por outro lado, a produção industrial não carrega a força da permanência, mas da contingência da formação de uma área de densidade de produção industrial, mais que da realização de um processo de industrialização consolidado.

\section{FECHANDO O TEXTO}

A proposta inicial, deste texto, era mostrar como a produção industrial é um fato na economia brasileira, mesmo em áreas onde sua participação não se destaca. No caso do Nordeste, a disseminação do modo industrial evidencia-se por vários ramos da indústria de bens não duráveis, sustentando o consumo na região e em outras partes do Brasil e do mundo. A produção, que se realiza em termos flexíveis (mantendo traços do fordismo), não se restringe à área urbana, mas se articula com as áreas rurais dos municípios que se articulam, por sua vez, numa relação heterárquica na rede urbana. As cidades pequenas são tomadas pela indústria, mesmo que de maneira precária. Isso leva à persistência da indústria que ocorre dependendo da conjuntura da economia nacional e estadual, da capacidade do empresário superar e responder às crises, fatores constantes no sistema capitalista. Enfim, voltando a insistir na proposta de leitura da industrialização brasileira e suas características em diferentes territórios, a disseminação do modo industrial não se faz por acaso, mas segundo vários fatores e momentos, como foi exposto no quadro I (que não serão repetidos, pois foram detalhados no item anterior). 
Esta proposta de leitura da dinâmica industrial brasileira não se restringe a um estudo de caso nem a uma estrutura rígida do que ocorre no país, mas precisa ser mais debatida e confrontada com outros exemplos para verificar como o fato empírico sustenta ou transforma a teoria.

\section{Referências bibliográficas}

CATELAN, Márcio José. Heterarquia urbana: Interações espaciais interescalares e cidades médias. São Paulo: Cultura Acadêmica, 2013.

DOMINGUES, Edson P. Aglomeração e periferias industriais no Brasil e no Nordeste. Revista Econômica do Nordeste. Fortaleza, v. 36, n. 4, out-dez de 2005.

HUBERMAN, Leo. História da riqueza do homem. Rio de Janeiro: Guanabara-Koogan, 1986.

PIRENNE, Henri. Historia económica y social de la Edad Media. México: Fondo de Cultura Económica, 1955.

SILVA, Joelma A. B. da. Dinâmica do emprego industrial nos municípios do Estado do Rio Grande do Norte, no período de 1994-2009. Brasília: IPEA, Code 2011, Anais do I Circuito de Debates Acadêmicos, 2011.

SILVEIRA NETO, R. M. Concentração Industrial Regional, Especialização Geográfica e Geografia Econômica. Revista Econômica do Nordeste, Fortaleza, v. 36, n.2, p. 189-208, abr.-jun. 2005.

SPOSITO, Eliseu Saverio; AZEVEDO, Francisco Fransualdo de. A disseminação do modo industrial em São Paulo e no Rio Grande do Norte: o tempo e o espaço em questão. Revista Formação, n. 23, v.1, 2016, p. 133-157.

Recebido em Novembro de 2017

Aprovado em Maio de 2018

Publicado em Julho de 2018 


\section{APÊNDICE 1}

\section{Fotos}

Fábrica e linha de produção em Caicó

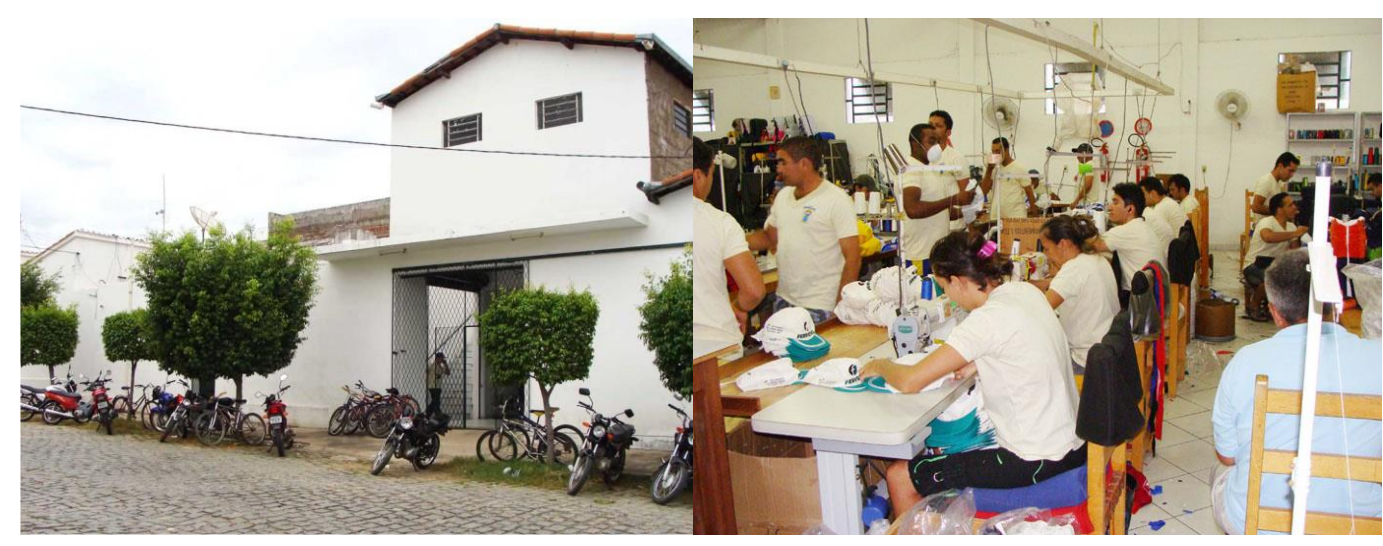

Fonte: http://www.bonesramalho.com.br/images/costura1.jpg (site corporativo)

Linha de produção de bonés em Caicó

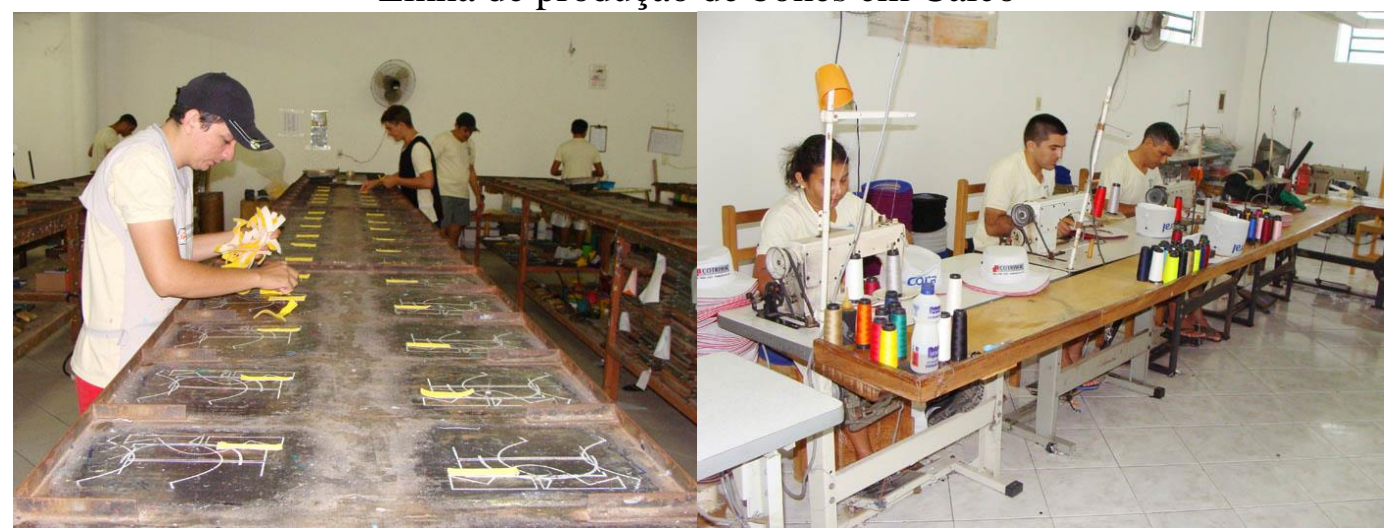

Fonte: http://www.bonesramalho.com.br/images/costura1.jpg (site corporativo)

Recebido em Novembro de 2017

Aprovado em Maio de 2018

Publicado em Julho de 2018 